\title{
Relative validation of a food frequency questionnaire to assess dietary fatty acid intake
}

\author{
Validación relativa de un cuestionario de frecuencia de alimentos para \\ evaluar la ingesta dietaria de ácido graso
}

\begin{abstract}
Objectives: This study aimed to develop and validate a Food Frequency Questionnaire (FFQ) for assessing consumption of fatty acids among pregnant women. Methods: Two lists of foods were created according to percent contribution of each nutrient estimated by three 24-hour recalls: a long and short version FFQ to estimate long-chain polyunsaturated fatty acids (LCPUFAs). Student paired t-test and Pearson correlation coefficients were used to verify the differences in mean consumption of nutrients from the FFQ and 24-hour recall. The concordance between the consumption values of the two methods was assessed using the Bland-Altman method and quartiles concordance. Results: For the FFQ long version, correlation values ranged from $0.33(p<0.05)$ to $0.62(p<0.01)$ for docosahexaenoic acid $(D H A)$ and linoleic acid (LA), respectively. Eicosapentaenoic acid (EPA) and docosapentaenoic acid (DPA) were not correlated. Exact concordance ranged from $49.0 \%$ (energy) to $22.4 \%$ (EPA), and discordance ranged from $14.3 \%$ (DPA) to $2.0 \%$ (Saturated). The FFQ - short version had high correlations for LCPUFAs. Exact concordance ranged from $36.7 \%$ ( $n-3$ LCPUFA) to $16.3 \%$ (DHA); and discordance from $12.2 \%$ (DPA) to $2.0 \%$ (arachidonic acid). Bland-Altman analysis showed good concordance for both versions. Conclusion: This nutrient-specific FFQ is a valid instrument to be used to estimate the level of consumption of fatty acids among pregnant women.

Keywords: Dietary assessment; Food Frequency Questionnaire; Long-chain polyunsaturated fatty acids; Pregnant; Relative validation.
\end{abstract}

\section{RESUMEN}

Objetivo: Este estudio tuvo como objetivo desarrollar y validar un cuestionario de frecuencia de consumo de alimentos para evaluar el consumo de ácidos grasos en gestantes. Métodos: Dos listas de alimentos fueron creadas de acuerdo con la contribución porcentual de cada nutriente estimado por 3 recordatorios de 24 horas: CFC - versión larga y CFC versión corta para estimar ácidos grasos poliinsaturados de cadena larga (AGPICL). La prueba de t pareada de Student y el coeficiente de correlación de Pearson se utilizaron para
Gisele Queiroz Carvalho ${ }^{1 *}$, Marcos Pereira², Jerusa M. Santana ${ }^{3}$, Iuri D. Louro ${ }^{4}$, Djanilson B. Santos ${ }^{5}$.

1. Universidade Federal de Juiz De Fora - Campus Avançado de
Governador Valadares.
Department of Nutrition. Governador Valadares, Brazil
2. Universidade Federal da Bahia. Collective Health Institute. Salvador, Brazil
3. Universidade Federal da Bahia. Department of Nutrition Sciences.
Salvador, Brazil
4. Universidade Federal do Espirito Santo. Center of Human and
Molecular Genetics. Vitória, Brazil
Center of Health Sciences. Santo Antônio de Jesus, Brazil.

*Corresponding author: Gisele Queiroz Carvalho.

Federal University of Juiz de For a,

Advanced Campus of Governador Valadares.

Department of Nutrition. Av. Dr. Raimundo Monteiro Rezende, 330, Centro, Governador Valadares, MG, Brazil. Email: gisele_qc@yahoo.com.br

Este trabajo fue recibido el 07 de mayo de 2019. Aceptado con modificaciones: 16 de noviembre de 2019. Aceptado para ser publicado: 13 de enero de 2020.

verificar las diferencias entre el consumo medio de nutrientes de del CFC y el recordatorio de 24 horas. La concordancia entre los valores de consumo de los dos métodos se evaluó mediante el método de Bland-Altman y la concordancia de cuartiles. Resultados: En CFC - versión larga, los valores de correlación oscilaron entre $0.33(p<0.05)$ y $0.62(p<0.01)$ para ácido docosahexaenoico (DHA) y ácido linoleico (LA), respectivamente. Ácido eicosapentaenoico (EPA) y ácido docosapentaenoico (DPA) no presentaron correlación. La concordancia exacta varió de $49,0 \%$ (energía) a 22,4\% (EPA), y la discordancia varió de $14,3 \%$ (DPA) a 2,0\% (saturado). CFC: la versión corta mostró los mejores valores de correlaciones para los AGPICL. La concordancia exacta varió de 36,7 (n-3 LCPUFA) a 16,3\% (DHA); y discordancia 
de 12,2\% (DPA) a 2,0\% (ácido araquidónico). El análisis de Bland-Altman mostró una buena concordancia para ambas versiones. Conclusión: Este método CFC específico de nutrientes es un instrumento válido que se utiliza para estimar el nivel de consumo de ácidos grasos en mujeres gestantes.

Palabras clave: Ácidos grasos poliinsaturados de cadena larga; Cuestionario de frecuencia alimentaria; Evaluación dietética; Gestantes; Validación relativa.

\section{INTRODUCTION}

Food intake during pregnancy influences gestational outcomes and the development or prevention of chronic diseases at different stages of life. As a result of the knowns health benefits, polyunsaturated fatty acids (PUFAs) have been widely studied, particularly long-chain polyunsaturated fatty acids (LCPUFAs), specifically: arachidonic acid (AA; 20:4 n-6), eicosapentaenoic acid (EPA; 22:6 n-3) and docosahexaenoic acid (DHA; 20:5 n-3), $1,2,3$. LCPUFAs influence the fluidity of the plasma membrane ${ }^{4}$, act in the formation and development of the retina and nervous system ${ }^{5}$ and are precursors of important substances in the regulation of inflammatory processes of the body ${ }^{3}$.

LCPUFAs content in blood and tissue mainly comes from eating, through the consumption of animal lipids such as poultry, fish, red meat, eggs and human breast milk. EPA and DHA are present in algae and foods of animal origin, especially fish; AA can be found in meat, poultry and eggs ${ }^{6}$. The endogenous synthesis of LCPUFAs from its precursor, $\alpha$-linoleic acid (ALA, 18:3 n-3) and linoleic acid (LA; $18: 2 \mathrm{n}-6)$, is also possibly mediated by $\Delta 5$-desaturase enzymes and $\Delta 6$-desaturase ${ }^{7,8}$. The main dietary sources are the oils extracted from seeds and oleaginous, such as: linseed, canola and soybean oils, for ALA, and sunflower, safflower, corn, soybean, peanut and palm oils, for $\mathrm{LA}^{6}$.

During pregnancy, adequate intake of omega-3 LCPUFA ( $n-3$ LCPUFA) guarantees meeting fetal needs and avoiding deficiencies ${ }^{9}$. During intrauterine life, a large amount of n-3 LCPUFA deposition in the retina and brain tissue of the fetus occurs, especially in the third trimester of pregnancy ${ }^{9}$. Other benefits of n-3 LCPUFA during pregnancy include a lower incidence of allergies and asthmatic diseases in children during childhood ${ }^{10,11}$ and proper fetal growth, although evidence is limited and the results of the studies are inconclusive ${ }^{12,13}$.

Studies linking consumption of LCPUFAs to health benefits in gestation and childhood are important for the production of new knowledge, if they are associated with the use of instruments for the accurate estimation of the consumption of fatty acids. One of the instruments most commonly used in dietary studies on food consumption is the Food Frequency Questionnaire (FFQ), which needs to be tested for its validity to estimate the nutrient of interest $^{14,15}$. However, some FFQ are extensive and may introduce bias in the assessment of food consumption. Therefore, the development of a reliable and validated FFQ, which can be easily applied to evaluate nutrient and food groups consumption in epidemiological studies, becomes relevant. Thus, this study aimed to develop and validate a FFQ for assessing the consumption of fatty acids among pregnant women.

\section{MATERIALS AND METHODS Study design and sample}

The objective of this study was to develop and evaluate the relative validation of Food Frequency Questionnaire to estimate the consumption of total lipids and fatty acids, with emphasis on the main LCPUFAs (n-3 and n-6) among pregnant women.

We included clinically healthy pregnant women from the NISAMI (Núcleo de Investigação em Saúde Materno Infantil) cohort of pregnant women. For the validation study, data were collected from pregnant women monitored between August 2013 and July 2014, in Santo Antônio de Jesus, Bahia, Brazil.

During the study period, the food consumption of 250 pregnant women were monitored and approximately 50 of them answered the FFQ and three $24 \mathrm{hr}$ dietary recalls. This sample size was appropriate to simultaneously assess repeatability and validity ${ }^{14}$.

The study was approved by the Human Research Ethics Committee of the Federal University of Recôncavo da Bahia, Bahia, Brazil. Women were eighteen years or older, gestational age $\leq 32$ weeks at the first interview, residents of the urban area, received prenatal care in the public health service of the city, and were not consuming a vegan diet (not consuming any animal foods).

In the first evaluation, women answered the FFQ and the first $24 \mathrm{hr}$ dietary recall. Women were weighed and height measured by the research team, in triplicate, according to techniques recommended by Jelliffe ${ }^{16}$. Gestational age was calculated based on the last menstrual period, or obtained by ultrasonography, if present. The second and third $24 \mathrm{hr}$ dietary recalls were applied in the pregnant woman's home, at intervals of 15 to 40 days between questionnaires.

\section{4-hour dietary recall}

Pregnant women reported to interviewers all foods and beverages consumed the day before, from the moment they woke up to the time they went to sleep. To assess the amount of food consumed, an album containing photographs of various appliances with household measures was used (e.g., full tablespoon, level tablespoon, etc.) or portions of food (S, $\mathrm{M}$ or $\mathrm{L})^{17}$. When in the pregnant woman's house, the interviewer asked permission to view the utensil used in preparation or during consumption.

In order to estimate nutrients consumption, food consumed reported in household measures was converted to grams or milliliters ${ }^{18,19}$. Data analysis was made considering the average nutrient energy intake an $d$ the three $24 \mathrm{hr}$ dietary recalls (24HR1, 24HR2 and 24HR3). 


\section{Food-frequency questionnaire development and analysis}

A semi-quantitative nutrient-specific FFQ was created to estimate the consumption of lipids, with a special focus on LCPUFAs. Initially, a list of the main food sources of $n-3$ LCPUFA $^{20,21}$ was selected. Foods with a PUFA content of $\geq$ $0.1 \mathrm{~g} / 100 \mathrm{~g}^{22}$ and lipid sources were also considered, which were known to be consumed by this population.

The list was mostly composed of products of animal origin, such as: meat (pork or beef), poultry, eggs, offal, sausages, fish and seafood, and regional foods. Foods of plant origin included were: vegetable oils, oilseeds and seeds. Regarding cereals, fruits and other vegetables, we considered only those with a recognized contribution of PUFAs, such as whole grains, some fruits, legumes, oilseeds and some leafy vegetables (raw, boiled or braised). Preparation options or types of food were included, making it possible for pregnant women to indicate among fried, baked, cooked or raw items; with or without skin; with bone or boneless; whole, semi-skimmed or skimmed milk.

Thus, 114 foods were selected, available in 213 items for selection and available in 11 food groups (milk and dairy, meat and eggs, oils and fats; snacks and canned goods, cereals, tubers and roots, legumes and oilseeds, vegetables, spices and condiments; sugars and sweets; beverages; regional foods). The frequency of consumption options was composed of 13 possible answers ranging from rarely/ never to $\geq 3$ times per day. To define the amount ingested, each food was presented through portions, in household measures, usually used for this population, based on $24 \mathrm{hr}$ dietary recalls applied at other times by researchers (e g. full double cup, full tablespoon, etc.). To determine the portions of the weights, household measures were converted into grams or milliliters ${ }^{18,19}$.

The final food list for the FFQ was developed from the intake analysis from the three dietary recalls. Using the formula in Block et al. ${ }^{23}$, foods were grouped into lists according to percent contribution, in descending order, of the nutrients of interest. The foods that contributed with at least $90 \%$ of each nutrient intake were included in the questionnaire ${ }^{23}$.

The relative contribution of a particular food was then given by ${ }^{23}$ :

Total nutrient (e.g., cholesterol) provided by particular food $x 100$

Total nutrient (e.g., cholesterol) provided by particular food

Twenty-seven foods that contributed with almost $100 \%$ of n-3 LCPUFA and with approximately $84 \%$ of AA composed the FFQ - short version. As these 27 foods had an insufficient contribution to the other nutrients, a FFQ - long version was created, consisting of the 27 food items from the FFQ - short version in addition to 60 second-ranked foods containing polyunsaturated fatty acids. "Cooked plantain" and "skim milk" were also added, as they were part of normal regional consumption of the population, and contributed to the total consumption of lipids, resulting in a list of 89 options for the FFQ - long version (Table 1). When considering the energy contribution of the food, it is observed that even foods with low nutrient content are included due to the high frequency of ingestion ${ }^{24}$.

For statistical analysis, each food contained in the final version of the FFQ was converted to daily consumption, considering the frequency of consumption and the number of servings reported by pregnant women. This step was initially in the processing of each frequency of consumption reported in daily frequency. For example, a constant of 1 was considered for foods consumed once per day; a constant of 2 when consumption was 2 times a day, and so forth. The weekly frequency was divided by 7 and by 30 for monthly frequency, thus finding the constant for each daily food intake. For the response option "rarely/never consume" the constant of 0 was used. Next, each constant, which indicated the daily frequency of consumption of each food, was multiplied by the amount of food consumed. The final product corresponded to the daily amount in grams or milliliters, of the food consumed by pregnant women.

\section{Nutrients intake analysis}

Questionnaires were tabulated and analyzed in Excel 2010 software. To estimate consumption of energy and nutrients in the three 24-hour recalls and FFQ, the Brazilian Food Composition Table was used ${ }^{25}$. For mixed foods, nutrients were estimated according to ingredients ${ }^{15}$. When a food or nutrient was not found in the Brazilian Food Composition Table, the National Nutrient Database for Standard Reference of the United States Department of Agriculture-USDA was used ${ }^{26}$. Consumption questionnaires provided information about energy, total lipids, and fatty acids: saturated, monounsaturated, polyunsaturated, LA (18:2 $n-6)$, AA (20:4 n-6), ALA (18:3 n-3), EPA (20:5 n-3), DHA (22:6 n-3), and DPA (22:5 n-3). Following the methodology used by other authors ${ }^{27,28}$, total intake of: $\mathrm{n}-3$ LCPUFA (Total n-3 LCPUFA: EPA + DHA + DPA), n-3 PUFA (Total n-3 PUFA: ALA + EPA + DHA + DPA), and n-6 PUFA (Total n-6 PUFA: LA + AA) were estimated.

Energy consumption was estimated to identify and exclude pregnant women with extreme and improbable consumption reported on the dietary recalls: less than $700 \mathrm{kcal}$ or greater than $5.000 \mathrm{kcal}^{29}$. This criterion was not used for the FFQ, since this was a specific nutrient instrument, in which foods with high energy and low in lipids were excluded, such as refined grains and various fruits.

\section{Statistical analysis}

The questionnaires were tabulated in Excel 2010 and the data analyzed using IBM SPSS Statistics 20. For dietary recalls, average values were used for food intake over the three days of consumption. Crude values of energy and nutrients were used for data analysis, except for correlation analysis, when the crude data and energy-adjusted by the residual method were used ${ }^{30}$, with energy intake as the 
independent variable and nutrient intake as the dependent variable.

The Shapiro-Wilk test was used to assess whether variables had a normal distribution. Non-normally distributed data for nutrients were log-transformed. The paired t-test was used to verify the differences in consumption average between the two instruments. Pearson correlation coefficients were estimated for energy and nutrients from the FFQ and $24 \mathrm{hr}$ dietary recall. For dietary survey verification, the following cutoffs for correlation strength were considered: poor $(<$ 0.30 ), acceptable (0.30 to 0.50$)$, good (0.51 to 0.70$)$ and very good $(>0.70)^{31}$. Correlation values considered moderate ranged from 0.40 to $0.70^{30}$.

Concordance between the consumption values of the two methods was assessed using the Bland-Altman method ${ }^{32}$, which is based on a dispersion graph for analysis of the relationship of discordance with assessed measures. On the $x$ axis, the average values of the two methods $(x+y) / 2$ are plotted and the $y$ axis contains the difference (or bias) between them $(x-y)$. The average difference between these two measurements and the Bland-Altman limits of agreement (LoA) were calculated (average difference of

Table 1. Percent contribution of the total fatty acids and energy intake from food mentioned in the three $24 \mathrm{hr}$ dietary recalls and FFQ - long version (89 foods) and short version ( 27 foods) among pregnant women $(n=49)$.

FFQ - Short Version (\%)

27 foods

Grams

Saturated

MUFA

PUFA

n-3 PUFA

ALA

EPA

DPA

DHA

Total n-3 PUFA

Total n-3 LCPUFA

n-6 PUFA

LA

AA

Total n-6 PUFA

Cholesterol

Total Lipids

Energy
26.4

83.8*

27.2

63.0

35.4

21.8
13.4

33.8

40.2

28.6

26.4

89.4**

$99.4^{* *}$

99.4**

$99.6^{* *}$

$99.6^{* *}$

$96.8^{* *}$

$96.8^{* *}$

38.6

$91.2^{* *}$

$97.6^{* *}$

$97.6^{* *}$
48.4

$92.2^{* *}$

$92.4^{* *}$

89.4**
89.0**

93.0**

89.0**

$90.2^{* *}$

$91.6^{* *}$

67.4

MUFA : Monounsaturated fatty acids ; PUFA: Polyunsaturated Fatty Acids; n-3 PUFA: n-3 Polyunsaturated fatty acids; ALA: $\alpha$ - Linolenic acid (18: 3 n-3); EPA: Eicosapentaenoic Acid (20:5 n-3); DPA: Docosapentaenoic acid (22: 5 n-3); DHA: Docosahexaenoic acid (22: 6 n-3); Total n-3 PUFA: ALA + EPA + DPA + DHA; Total n-3 LCPUFA: EPA + DPA + DHA; n-6 PUFA: n-6 Polyunsaturated Fatty Acids; LA: Linoleic acid (18: 2 n-6); AA: Arachidonic acid (20: 4 n-6).

* Percentage of food contribution higher than $80 \%$ of total nutrients in the three $24 \mathrm{hr}$ dietary recalls.

** Percentage of food contribution higher than $89 \%$ of total nutrients in the three $24 \mathrm{hr}$ dietary recalls.

$\%=$ Percent contribution of the foods listed in the FFQ - long version and FFQ - short version in relation to total nutrients (see methods). 
$1.96 \mathrm{SD}$ ) and plotted on the graph. A good concordance between the methods is considered when more than $95 \%$ of the differences of the measures are within the $\mathrm{LoA}^{33}$.

The quartiles concordance analysis of consumption between the methods was used to assess the ability to classify the level of consumption of each pregnant woman. According to the nutrient consumption level of the two methods, the proportion of exact concordance (pregnant women classified in the same quartile) and the discordance level (pregnant women classified in opposite quartiles) was calculated $^{34,35}$.

\section{RESULTS}

Fifty-one pregnant women answered the FFQ and the three $24 \mathrm{hr}$ dietary recalls. After estimating the daily energy intake obtained by the average consumption of the dietary recalls, one pregnant woman was excluded for presenting average consumption of less than $700 \mathrm{kcal}$ energy and another for having consumption of more than 5.000 Kcal. In summary, forty-nine pregnant women were included; the mean age was $28 \pm 5.8$ years; the mean weight was $69.4 \pm 12.4 \mathrm{~kg}$; the mean height was $1.60 \pm 0.07$ meters; the mean $\mathrm{BMI}$ was $27.0 \pm 4.8 \mathrm{~kg} / \mathrm{m}^{2}$, with a mean gestational age of $27.6 \pm 5.8$ weeks. Most pregnant women $(n=42 ; 85.7 \%)$ were black or mixed and had finished high school $(n=30$; $61.2 \%$, with approximately 11 years of study.

The mean nutrient intake was higher in the FFQ - long version, compared to the mean intake of the three 24 dietary recalls $(p<0.05)$, except for EPA, DPA and energy with no differences in average values. The FFQ - short version, only used in the validation of LCPUFAs, showed no difference in average nutrient intake between the two instruments (Table 2).

The crude and energy-adjusted correlation coefficients

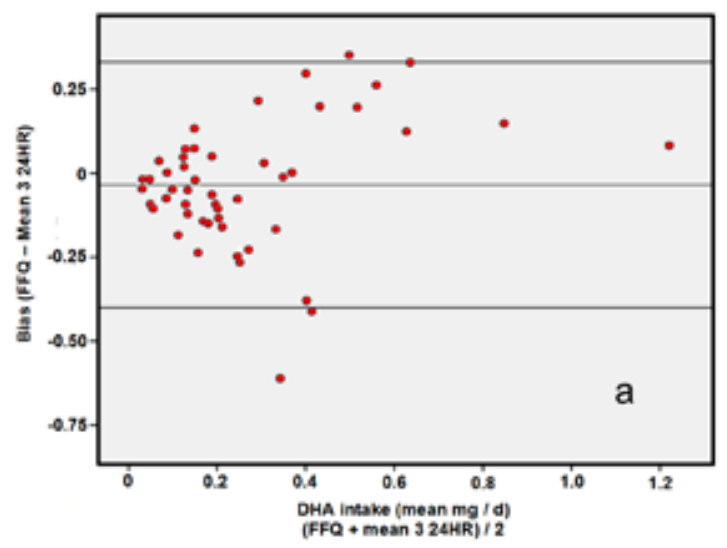

are shown in table 2. For crude values of the FFQ - long version, correlations show acceptable or moderate values for nearly all nutrients, ranging from 0.329 to DHA ( $P$ $<0.05)$ and 0.617 to LA ( $\mathrm{p}<0.01)$. Total $n-3$ LCPUFA, AA and cholesterol showed weak correlations, although not statistically significant, while EPA and DPA were not correlated. When the data were adjusted by energy, there was a tendency to reduce the correlations values, mainly affecting n-3 PUFAs, which lost statistical significance for ALA, DHA and total n-3 PUFA.

The FFQ - short version showed better results for LCPUFAs, with acceptable or moderate correlations with DHA $(p<0.01)$, total LCPUFA $n-3$ and AA $(p<0.05)$ and poor correlations with EPA and DPA, although not statistically significant. The energy-adjustment of these nutrients was also responsible for the lack of correlations in comparison to crude data, with a loss of statistical significance for DHA and total n-3 LCPUFA (Table 2).

The Bland-Altman analysis showed good concordance between the FFQ - long and short versions - and the average of the three $24 \mathrm{hr}$ recalls, with more than $95 \%$ of the differences of the measures within the LoA (Figure 1). Only LA, AA and n-6 PUFA Total in the FFQ - long version showed lower agreement, with $71 \%(n=14)$ of the differences of the measures within the LoA (Table 3).

Table 3 shows the exact concordance (pregnant women classified in the same quartile) and discordance (pregnant women classified in opposite quartiles) between the FFQ and the average of the three $24 \mathrm{hr}$ recalls. When using the FFQ - long version, the exact concordance ranged from $49.0 \%$ for energy to $22.4 \%$ for EPA; discordance ranged from $14.3 \%$ for DPA to $2.0 \%$ for saturated fatty acid.

The FFQ - short version slightly altered the results for the LCPUFAs, with mostly positive changes. There was a

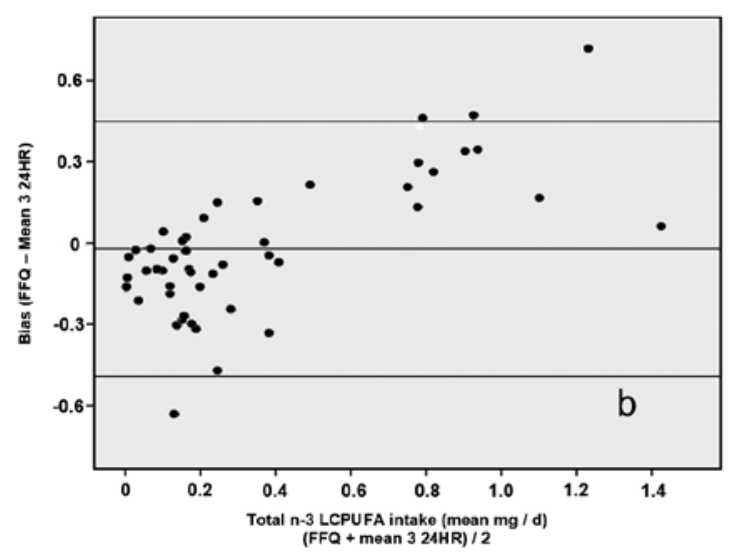

Figure 1: Agreement between the FFQ - short version and the mean intake of three 24-hour recall (24HR) (mg / d) in estimates of a) Docosahexaenoic acid (DHA) intakes and b) Total n-3 LCPUFA intakes as assessed by the Bland-Altman technique (see methods). 
Table 2. Lipids and energy intake according to FFQ - long version ( 89 foods) and short version ( 27 foods) - and $24 \mathrm{hr}$ dietary recall, and Pearson Correlation Coefficient between the methods among pregnant women $(n=49)$.

\begin{tabular}{|c|c|c|c|c|c|c|}
\hline \multirow[t]{2}{*}{ Nutrients } & \multicolumn{2}{|c|}{ FFQ (Crude) } & \multicolumn{2}{|c|}{ 24hr dietary recall (Crude) } & \multicolumn{2}{|c|}{$\begin{array}{l}\text { Pearson Correlation } \\
\text { Coefficient }(r=)\end{array}$} \\
\hline & Mean & SD & Mean & SD & Crude & Adjusted $^{1}$ \\
\hline \multicolumn{7}{|l|}{ FFQ - Long Version } \\
\hline Saturated (g) & $38.0^{+}$ & 18.4 & $26.2^{\dagger}$ & 10.4 & $0.517^{* *}$ & $0.368^{* *}$ \\
\hline MUFA (g) & $32.8^{+}$ & 16.0 & $21.6^{+}$ & 9.6 & $0.584^{* *}$ & $0.421^{* *}$ \\
\hline PUFA (g) & $20.6^{+}$ & 9.94 & $12.4^{+}$ & 6.2 & $0.606^{* *}$ & $0.400^{* *}$ \\
\hline \multicolumn{7}{|l|}{ n-3 PUFA } \\
\hline $\mathrm{ALA}(\mathrm{mg})$ & $1.87^{\dagger}$ & 0.89 & $1.16^{+}$ & 0.510 & $0.466^{* *}$ & 0.234 \\
\hline EPA (mg) & 0.060 & 0.060 & 0.042 & 0.053 & -0.103 & -0.115 \\
\hline DPA (mg) & 0.038 & 0.050 & 0.026 & 0.046 & -0.051 & -0.041 \\
\hline DHA (mg) & $0.231^{+}$ & 0.174 & $0.167^{+}$ & 0.181 & $0.329^{*}$ & 0.221 \\
\hline Total n-3 PUFA (mg) & $2.20^{+}$ & 1.02 & $1.40^{+}$ & 0.652 & $0.455^{* *}$ & 0.221 \\
\hline Total n-3 LCPUFA (mg) & $0.330^{+}$ & 0.232 & $0.235^{+}$ & 0.237 & 0.174 & 0.091 \\
\hline \multicolumn{7}{|l|}{ n-6 PUFA } \\
\hline $\mathrm{LA}(\mathrm{mg})$ & $18.0^{+}$ & 9,0 & $10.8^{+}$ & 5.46 & $0.617 * *$ & $0.414^{* *}$ \\
\hline $\mathrm{AA}(\mathrm{mg})$ & $0.212^{+}$ & 0.208 & $0.143^{+}$ & 0.136 & 0.263 & 0.257 \\
\hline Total n-6 PUFA (mg) & $18.2^{+}$ & 9.0 & $11.0^{+}$ & 5.50 & $0.614^{* *}$ & $0.406^{* *}$ \\
\hline Cholesterol (mg) & $466^{+}$ & 254 & $342^{+}$ & 184 & 0.255 & 0.192 \\
\hline Total Lipids (g) & $104^{+}$ & 47.4 & $70.0^{+}$ & 28.2 & $0.573^{* *}$ & $0.404^{* *}$ \\
\hline Energy & 2266 & 952 & 2170 & 562 & - & - \\
\hline \multicolumn{7}{|l|}{ FFQ -Short version } \\
\hline \multicolumn{7}{|l|}{ n-3 PUFA } \\
\hline EPA (mg) & 0.037 & 0.025 & 0.042 & 0.053 & 0.091 & 0.010 \\
\hline DPA (mg) & 0.017 & 0.022 & 0.026 & 0.046 & 0.121 & 0.116 \\
\hline $\mathrm{DHA}(\mathrm{mg})$ & 0.202 & 0.163 & 0.167 & 0.181 & $0.404^{* *}$ & 0.277 \\
\hline Total n-3 LCPUFA (mg) & 0.256 & 0.188 & 0.235 & 0.237 & $0.324^{*}$ & 0.191 \\
\hline \multicolumn{7}{|l|}{ n-6 PUFA } \\
\hline $\mathrm{AA}(\mathrm{mg})$ & 0.164 & 0.167 & 0.143 & 0.136 & $0.358^{*}$ & $0.334^{*}$ \\
\hline
\end{tabular}

MUFA : Monounsaturated fatty acids ; PUFA: Polyunsaturated Fatty Acids; n-3 PUFA: n-3 Polyunsaturated fatty acids; ALA: $\alpha$ - Linolenic acid (18: 3 n-3); EPA: Eicosapentaenoic Acid (20:5n-3); DPA: Docosapentaenoic acid (22: 5 n-3); DHA: Docosahexaenoic acid (22 : 6 n-3); Total n-3 PUFA: ALA + EPA + DPA + DHA; Total n-3 LCPUFA: EPA + DPA + DHA; n-6 PUFA: n-6 Polyunsaturated Fatty Acids; LA: Linoleic acid (18:2 n-6); AA: Arachidonic acid (20:4 n-6).

1 The nutrients intake was adjusted for total energy consumption for the residual method.

${ }^{+} p<0.05$ for the paired $t$ test for differences between the FFQ and the average of the three $24 \mathrm{HR}$.

* Significant at $\mathrm{p}<0.05$

** Significant at $\mathrm{p}<0$

reduction in the discordance for EPA and DPA, without affecting the proportion of exact concordance. Opposite results were shown with DHA. Exact concordance increased and discordance reduced total n-3 LCPUFA and AA, with the most significant change to total n-3 LCPUFA. The exact concordance ranged from $36.7 \%$ for total n-3 LCPUFA to $16.3 \%$ for DHA; discordance ranged from $12.2 \%$ to $2.0 \%$ for DPA and AA, respectively (Table 3). 
Table 3. Concordance of lipid intake estimated by FFQ - long version (89 foods) and short version (27 foods) - compared to the mean intake of three $24 \mathrm{hr}$ dietary recalls among pregnant women $(n=49)$, in Santo Antônio de Jesus, Bahia, Brazil, 2015.

\begin{tabular}{|c|c|c|c|c|c|}
\hline \multirow{2}{*}{ Nutrients } & \multirow{2}{*}{$\begin{array}{l}\text { Bland-Altma } \\
\text { Mean } \\
\text { difference }^{1}\end{array}$} & \multirow[b]{2}{*}{$\begin{array}{l}\text { Lower } \operatorname{LoA}^{2} \\
\quad \text { ratio }\end{array}$} & \multirow[b]{2}{*}{$\begin{array}{l}\text { Upper LoA } \\
\text { ratio }\end{array}$} & \multicolumn{2}{|c|}{ Inter-quartile agreement } \\
\hline & & & & $\begin{array}{c}\text { Same Quartile } \\
(\%)\end{array}$ & $\begin{array}{c}\text { Extreme quartile } \\
(\%)\end{array}$ \\
\hline \multicolumn{6}{|l|}{ FFQ - Long Version } \\
\hline Saturated (g) & -11.6 & -42.6 & 19.4 & 36.7 & 2.0 \\
\hline Monounsaturated (g) & -11.2 & -36.4 & 14.2 & 34.7 & 6.1 \\
\hline Polyunsaturated (g) & -8.15 & -23.6 & 7.34 & 38.8 & 6.1 \\
\hline \multicolumn{6}{|l|}{ (n-3) PUFA } \\
\hline ALA (mg) & -0.710 & -2.25 & 0.840 & 32.7 & 6.1 \\
\hline EPA (mg) & -0.300 & -1.56 & 0.960 & 22.4 & 10.2 \\
\hline DPA (mg) & 0.820 & -1.88 & 1.37 & 26.5 & 14.3 \\
\hline $\mathrm{DHA}(\mathrm{mg})$ & -0.290 & -1.52 & 0.950 & 24.5 & 8.2 \\
\hline Total n-3 PUFA (mg) & -0.800 & -2.61 & 1.00 & 36.7 & 6.1 \\
\hline Total n-3 LCPUFA (mg) & -0.310 & -1.52 & 0.910 & 26.5 & 10.2 \\
\hline \multicolumn{6}{|l|}{ (n-6) PUFA } \\
\hline LA (mg) & -7.19 & -14.4 & 0.110 & 40.8 & 6.1 \\
\hline $\mathrm{AA}(\mathrm{mg})$ & -0.170 & -0.600 & 0.270 & 24.5 & 6.1 \\
\hline Total n-6 PUFA (mg) & -7.26 & -14.6 & 0.030 & 44.9 & 6.1 \\
\hline Cholesterol (mg) & -124 & -658 & 410 & 36.7 & 4.1 \\
\hline Lipídeos (g) & -34.8 & -110 & 41.6 & 42.9 & 4.1 \\
\hline \multicolumn{6}{|l|}{ FFQ -Short version } \\
\hline \multicolumn{6}{|l|}{ (n-3) PUFA } \\
\hline EPA (mg) & 0.005 & -0.110 & 0.110 & 22.4 & 6.1 \\
\hline DPA (mg) & 0.008 & -0.090 & 0.100 & 26.5 & 12.2 \\
\hline $\mathrm{DHA}(\mathrm{mg})$ & -0.034 & -0.400 & 0.330 & 16.3 & 8.2 \\
\hline Total n-3 LCPUFA (mg) & -0.022 & -0.490 & 0.450 & 36.7 & 6.1 \\
\hline \multicolumn{6}{|l|}{ (n-6) PUFA } \\
\hline $\mathrm{AA}(\mathrm{mg})$ & -0.021 & -0.360 & 0.320 & 26.5 & 2.0 \\
\hline
\end{tabular}

MUFA : Monounsaturated fatty acids ; PUFA: Polyunsaturated Fatty Acids; n-3 PUFA: n-3 Polyunsaturated fatty acids; ALA: $\alpha$ - Linolenic acid (18: 3 n-3); EPA: Eicosapentaenoic Acid (20:5 n-3); DPA: Docosapentaenoic acid (22:5n-3); DHA: Docosahexaenoic acid (22:6 n-3); Total n-3 PUFA: ALA + EPA + DPA + DHA; Total n-3 LCPUFA: EPA + DPA + DHA; n-6 PUFA: n-6 Polyunsaturated Fatty Acids; LA: Linoleic acid (18:2 n-6); AA: Arachidonic acid (20:4 n-6).

${ }^{1}$ Mean difference $=$ Average difference between: $\left.a\right)$ the difference (or bias) between the two methods $(x-y)$ and $b$ ) the average values of the two methods $(x+y) / 2$.

${ }^{2} \mathrm{LoA}=$ limits of concordance (average difference $\pm 1.96 \mathrm{SD}$ ) 


\section{DISCUSSION}

In the present study, the semi-quantitative FFQ developed to estimate the consumption of total lipids and fatty acids showed good validity when compared to three $24 \mathrm{hr}$ dietary recalls. The shorter version with 27 foods enables agility to estimate the LCPUFA consumption. The long form is more time consuming, but allows for the estimation of other fatty acids (saturated fatty acids, monounsaturated, polyunsaturated, LA, ALA, AA, DHA, Total n-6 PUFA, Total n-3 PUFA, Total n-3 LCPUFA, cholesterol and total lipids).

The average consumption of nutrients assessed by the FFQ - long version was overestimated as compared to the 24hr recall, except for EPA and DPA. On the other hand, there was no significant difference in the intake of LCPUFA between the FFQ - short version and the average of the three $24 \mathrm{hr}$ recalls. Most FFQ overestimate nutrient intake compared to others dietary instruments ${ }^{15,34,36}$. Thus, the short version of our instrument may be an alternative to avoid bias in the analysis of food consumption in epidemiological studies with pregnant women.

The difference in the average intake value among the instruments is attributed, in part, to the inherent characteristics of the data capture method, since the $24 \mathrm{hr}$ dietary recall provides recent information about food consumption while FFQ estimates long-term eating habits ${ }^{36}$. The present FFQ was developed to estimate food consumption from the start of pregnancy, which means less time to estimate nutrient intake. Gunes et al. ${ }^{36}$ suggested that a shorter FFQ coverage period may reduce the difference between the values of the two instruments. Other factors such as the availability of some seasonal foods presented in FFQ and excessive reporting of foods that are considered healthy or highcalorie specific food items such as bread and cereals, are also cited as a possible reason for the trend in the FFQ to overestimate food intake ${ }^{15}$.

On the other hand, nutrient intake is underestimated by food records due to 1) underreporting in the weighed food record or 2) lower food intake during the study period, as many subjects tend to simplify the weighing process or report lower intakes to impress the researchers. Thus, considering the possible overestimation in the FFQ and underreporting in standard dietary instruments, it is possible that the true intake is between the values estimated by these two instruments. Researchers suggest, then, that it is possible that the difference between the true and estimated intake by FFQ is smaller than the difference between intake estimated from the FFQ and $24 \mathrm{hr}$ recall ${ }^{22}$.

The moderate correlation between the FFQ and the 24-hour record has also been reported in other studies $15,20,36$. For LCPUFA, correlation values were higher in the FFQ short version, which had only 27 food sources of LCPUFA. According to some researchers, the nutrient - specific FFQ tends to be smaller, quick to complete, and show better results for nutrient intakes than developed FFQ to assess total dietary intake $^{20,24}$. It is suggested, however, that, as observed in the present study, energy adjustment may affect data analysis.
That is because foods present in the nutrient-specific FFQ had high nutrient density, as high caloric density foods, which are poor in these nutrients, were excluded. Moreover, it is possible that the $24 \mathrm{hr}$ dietary recalls have foods that have been excluded from the FFQ for being characterized as high caloric density and low estimated nutrient density, which may make the correlation weaker when dietary instruments are compared after energy adjustment.

Using the Bland-Altman graphs, we observed considerable data dispersion, however, we also observed excellent concordance between the two evaluated methods, with LA, AA and TOTAL n-6 PUFA showing smaller concordance on the FFQ - long version. Other studies have shown good concordance between the FFQ and dietary records or $24 \mathrm{hr}$ recalls ${ }^{20,36,37}$. According to Ingram et al..$^{22}$, it is common that LCPUFA show high consumption variability, since foods with high nutrient density are often not consumed daily. Thus, the individual who reported a moderate frequency of consumption of foods on the FFQ, such as fish and seafood, may have underestimated or overestimated consumption depending on the presence or absence of these foods in the $24 \mathrm{hr}$ dietary recall ${ }^{22}$.

The present study showed that the specific-nutrient FFQ has good exact concordance (pregnant women classified in the same quartile) and low discordance (pregnant women classified in opposite quartiles). Only DHA in the FFQ - short version and EPA and total n-3 LCPUFA in the FFQ - long version had slightly higher than $10 \%$ discordance, which is still acceptable. Studies on concordance of nutrient intake level have using quintiles ${ }^{15,22}$, quartiles ${ }^{37}$ or tertiles $^{38}$, and showed varying results, but generally also have good exact concordance and low discordance. The concordance evaluated by quartiles allows for grouping individuals who consume lower quantities of the evaluated nutrient, in comparison with those that have a greater consumption. This type of grouping is important mainly in epidemiological studies, which relate categories of nutrient consumption to the presence of diseases ${ }^{15}$.

In the present study, we used $24 \mathrm{hr}$ dietary recalls as the gold standard for analysis, since it is an instrument very easy and cheap to use, has a high response rate, does not interfere with food intake ${ }^{15}$ and has good correlation with biomarkers ${ }^{39}$. However, it depends on memory and the ability to report measures and portion intake ${ }^{15}$. To avoid the risk of bias, we used a food registration album, allowing us to obtain reliable measurements.

Among food questionnaires, dietary records, especially those using direct weighing, are instruments with a better ability to correctly estimate dietary intake, but they are not recommended for people with low or moderate education ${ }^{15}$, such as the population in the present study, therefore the use of $24 \mathrm{hr}$ dietary recalls is recommended .

Another important aspect was that we chose not to use fatty acid biomarkers to validate FFQ. This option was justified because biomarkers are considered less reliable for use in pregnant women because the plasma concentration 
of PUFAs in pregnancy is not only result of food intake but is also influenced by the increased volume of maternal plasma $^{40}$. Further studies are needed to determine the best biomarker to assess PUFA intake during pregnancy, in order to validate FFQ.

Relative validation is when a dietary instrument has good validity, such as Food Weighed Records and 24hr dietary recalls, compared with other dietary testing instruments to be validated. In this case, the greater the number of days evaluated by a standard diet instrument, the lower the error inherent in the use of intra-individual variability ${ }^{30}$. Thus, it was possible to obtain a tool with a good ability to estimate the consumption of fatty acids.

A limitation of the study was that the second FFQ, which would be applied by the third $24 \mathrm{hr}$ recall, was performed in a smaller number of women, mainly due to poor adherence of the study population. Although it is known that the FFQ estimates retrospective consumption, we chose to use the estimated average intake of the three $24 \mathrm{hr}$ dietary recalls, since the greater number of evaluated days improve the instrument's accuracy ${ }^{30}$. In addition, the time between the application of the FFQ and the second and third dietary recalls was small, it is possible that the three recalls adequately reported eating habits of women during pregnancy.

Other important aspects concerning the construction of the FFQ are worth mentioning. By choosing to build a nutrient-specific FFQ, the unique character of the instrument was assumed, which adequately evaluates the nutrient of interest but with possible inability to estimate the consumption of energy and other nutrients from the food of pregnant women. We acknowledge that the selection of foods and the final definition of the food list after applying all dietary questionnaires (FFQ and three $24 \mathrm{hr}$ dietary recalls) could lead to the absence of some foods commonly consumed by the population that are present in dietary recalls. Fortunately, few foods were not contemplated in the initially applied FFQ; and when this occurred, the percent contribution of fatty acid food was low, since care was taken to select food sources of LCPUFA, and sources of PUFA and total lipids, without compromising the quality of the FFQ developed.

\section{CONCLUSION}

Overall, though food consumption was overestimated, the FFQ showed moderate correlation and good concordance when compared with $24 \mathrm{hr}$ dietary recall. Preparing two versions of the FFQ, which can be applied simultaneously, was important as it allows for different data analysis according to the nutrient of interest and food intake assessment objectives. And, if desired, the short version allows for the evaluation of the consumption of sources of fatty acids with shorter application time and less risk of bias. Therefore, this semi-quantitative nutrient-specific FFQ is an acceptable and reliable instrument for use in epidemiological studies as a qualitative measure to assess the level of consumption of fatty acids in pregnant women.
Acknowledgments: Authors thanks the Conselho Nacional de Desenvolvimento Científico e Tecnológico CNPQ (CNPq Process: 481509/2012-7) for financial support.

\section{REFERENCES}

1. Su HY, Lee HC, Cheng WY, Huang SY. A calorie-restriction diet supplemented with fish oil and high-protein powder is associated with reduced severity of metabolic syndrome in obese women. Eur I Clin Nutr 2015; 69: 322-328.

2. Yoshihara T, Shimada K, Fukao K, et al. Omega 3 Polyunsaturated fatty acids suppress the development of aortic aneurysms through the inhibition of macrophage-mediated inflammation. Circ J 2015; 79: 1470-1478.

3. Weldon SM, Mullen AC, Loscher CE, Hurley LA, Roche HM. Docosahexaenoic acid induces an anti-inflammatory profile in lipopolysaccharide-stimulated human THP-1 macrophages more effectively than eicosapentaenoic acid. J Nutr Biochem 2007; 18: 250-258.

4. Jaureguiberry MS, Tricerri MA, Sanchez SA, et al. Role of plasma membrane lipid composition on cellular homeostasis: learning from cell line models expressing fatty acid desaturases. Acta Biochim Biophys Sin (Shanghai) 2014; 46: 273-282.

5. Qawasmi A, Landeros-Weisenberger A, Bloch MH. Metaanalysis of LCPUFA supplementation of infant formula and visual acuity. Pediatrics 2013; 131: e262-e272.

6. Huffman SL, Harika RK, Eilander A, Osendarp SJ. Essential fats: how do they affect growth and development of infants and young children in developing countries? A literature review. Matern Child Nutr 2011; 7 (Suppl. 3): 44-65.

7. Glaser C, Lattka E, Rzehak P, Steer C, Koletzko B. Genetic variation in polyunsaturated fatty acid metabolism and its potential relevance for human development and health. Matern Child Nutr 2011; 7: 27-40.

8. Koletzko B, Lattka E, Zeilinger S, Illig T, Steer C. Genetic variants of the fatty acid desaturase gene cluster predict amounts of red blood cell docosahexaenoic and other polyunsaturated fatty acids in pregnant women: findings from the Avon Longitudinal Study of Parents and Children. Am J Clin Nutr 2011; 93: 211-219.

9. Koletzko B, Cetin I, Brenna JT, et al. Dietary fat intakes for pregnant and lactating women. Br J Nutr 2007; 98: 873-877.

10. Noakes PS, Vlachava $M$, Kremmyda $L S$, et al. Increased intake of oily fish in pregnancy: effects on neonatal immune responses and on clinical outcomes in infants at $6 \mathrm{mo}$. Am J Clin Nutr 2012; 95: 395-404.

11. Olsen SF, Østerdal ML, Salvig JD, et al. Fish oil intake compared with olive oil intake in late pregnancy and asthma in the offspring: 16 y of registry-based follow-up from a randomized controlled trial. Am J Clin Nutr 2008; 88: 167-175.

12. Dunstan JA1, Simmer K, Dixon G, Prescott SL. Cognitive assessment of children at age 2(1/2) years after maternal fish oil supplementation in pregnancy: a randomized controlled trial. Arch Dis Child Fetal Neonatal Ed. 2008; 93: F45-F50.

13. van Eijsden $M$, Hornstra $G$, van der Wal MF, Vrijkotte TG, Bonsel G). Maternal n-3, n-6, and trans fatty acid profile early in pregnancy and term birth weight: a prospective cohort study. Am J Clin Nutr 2008; 87: 887-895.

14. Cade J, Thompson R, Burley V, Warm D. Development, validation and utilization of food-frequency questionnaires - a review. Public Health Nutr. 2002; 5: 567-87.

15. Mirmiran P, Esfahani FH, Mehrabi Y, Hedayati M, Azizi F. Reliability and relative validity of an FFQ for nutrients in the 
Tehran lipid and glucose study. Public Health Nutr 2010; 13: 654-662.

16. Jelliffe DB. Evaluación del estado de nutrición de la comunidad. Ginebra: Organización Mundial de La Salud. 1968.

17. Monteiro JP, Pfrimer K, Tremeschin MH, Molina MC, Chiarello P. Consumo Alimentar-Visualizando porções (Série Nutrição e Metabolismo). Rio de. Janeiro: Guanabara Koogan. 2007.

18. IBGE: Instituto Brasileiro de Geografia e Estatística. Pesquisa de Orçamentos Familiares - POF 2008-2010: Tabela de medidas referidas para os alimentos consumidos no Brasil. Instituto Brasileiro de Geografia e Estatística. 2011.

19. Pinheiro ABV, Lacerda EMA, Benzecry EH, Gomes MCS, Costa VM. Tabela para avaliação de consumo alimentar em medidas caseiras. Rio de Janeiro: Atheneu. 2005.

20. Sullivan BL, Brown J, Williams PG, Meyer BJ. Dietary validation of a new Australian food-frequency questionnaire that estimates long-chain n-3 polyunsaturated fatty acids. Br J Nutr 2008; 99: 660-666.

21. Lora KR, Lewis NM, Eskridge KM, Stanek-Krogstrand K, Ritter-Gooder P. Validity and reliability of an omega-3 fatty acid food frequency questionnaire for first-generation Midwestern Latinas. Nutr Res 2010; 30: 550-557.

22. Ingram MA, Stonehouse W, Russell KG, Meyer BJ, Kruger R. The New Zealand PUFA semiquantitative food frequency questionnaire is a valid and reliable tool to assess PUFA intakes in healthy New Zealand adults. I Nutr 2012; 142: 1968-1974.

23. Block G, Dresser CM, Hartman AM, Carroll MD. Nutrient sources in the American diet: quantitative data from the NHANES II survey. II. Macronutrients and fats. Am J Epidemiol 1985; 122: 27-40.

24. Meyer B. Re: Food-frequency questionnaire for assessing long-chain $\omega$-3 fatty-acid intake. Nutrition 2013; 29: 808809 .

25. NEPA-UNICAMP. Tabela brasileira de composição de alimentos / NEPA-UNICAMP - 4. ed. rev. e ampl. Campinas: NEPAUNICAMP. 2011.

26. USDA. U.S. Department of Agriculture, Agricultural Research Service. FoodData Central. 2020. Avaible https://fdc.nal. usda.gov [accessed on 13 march 2020].

27. Swierk M, Williams PG, Wilcox J, Russell KG, Meyer BJ. Validation of an Australian electronic food frequency questionnaire to measure polyunsaturated fatty acid intake. Nutrition 2011; 27: 641-646.

28. Orton HD, Szabo NJ, Clare-Salzler M, Norris JM. Comparison between omega-3 and omega- 6 polyunsaturated fatty acid intakes as assessed by a food frequency questionnaire and erythrocyte membrane fatty acid composition in young children. Eur J Clin Nutr 2008; 62: 733-738.

29. Paalanen L, Männistö S, Virtanen MJ, et al. Validity of a food frequency questionnaire varied by age and body mass index. J Clin Epidemiol 2006; 59: 994-1001.

30. Willett WC. Nutritional Epidemiology. New York: Oxford University Press. 1998.

31. Øverby NC, Serra-Majem L, Andersen LF. Dietary assessment methods on $n-3$ fatty acid intake: a systematic review. $\mathrm{Br}$ I Nutr 2009; 102 (Suppl 1): S56-S63.

32. Bland IM \& Altman DG. Statistical methods for assessing agreement between two methods of clinical measurement. Lancet. 1986; 1 (8476): 307-310.

33. Bland $M$ M A Altman DG. Statistical methods for assessing agreement between two methods of clinical measurement. Int I Nurs Stud 2010; 47: 931-936.

34. Zanolla AF, Olinto MTA, Henn RL, Wahrlich V, Anjos LA. Avaliação de reprodutibilidade e validade de um questionário de frequência alimentar em adultos residentes em Porto Alegre, Rio Grande do Sul, Brasil. Cad. Saúde Pública 2009; 25: 840-848.

35. Giacomello A, Schmidt MI, Nunes MAA, et al. Validação relativa de Questionário de Freqüência Alimentar em gestantes usuárias de serviços do Sistema Único de Saúde em dois municípios no Rio Grande do Sul, Brasil. Rev Bras Saúde Mater Infant 2008; 8: 445-454.

36. Gunes FE, Imeryuz N, Akalin A, et al. Development and validation of a semi-quantitative food frequency questionnaire to assess dietary intake in Turkish adults. J Pak Med Assoc 2015; 65: 756-763.

37. Patterson AC, Hogg RC, Kishi DM, Stark KD. Biomarker and dietary validation of a Canadian food frequency questionnaire to measure eicosapentaenoic and docosahexaenoic acid intakes from whole food, functional food, and nutraceutical sources. I Acad Nutr Diet 2012; 112: 1005-1014.

38. Molina MCB, Benseñor IM, Cardoso LO, et al. Reprodutibilidade e validade relativa do Questionário de Frequência Alimentar do ELSA-Brasil. Cad Saúde Pública 2013; 29: 379-389.

39. Parker G, McClure G, Hegarty BD, Smith IG. The validity of a food frequency questionnaire as a measure of PUFA status in pregnancy. BMC Pregnancy Childbirth 2015; 15: 60.

40. Wallin A, Di Giuseppe D, Burgaz A, et al. Validity of a food frequency questionnaire-based estimates of long-term longchain n-3 polyunsaturated fatty acid intake. Eur J Nutr 2014; 53: 549-555. 